\title{
Determining Maximum Load Carrying Capacity of 2-link Mechanical Manipulator Using GA and PSO Algorithms
}

\author{
NiushaShafiabady $^{1}$, Dino Isa ${ }^{1}$, M.A. NimaVakilian ${ }^{2}$ \\ University of Nottingham, Malaysia Campus
}

\begin{abstract}
This paper presents calculating the maximum load capacity of 2-link mechanical manipulator using evolutionary algorithms, PSO and GA, applied to the system's dynamic model. GA and PSO are two techniques that have received a lot of attention in recent years, owing to their parallel characteristics and their ability in searching for optimal solutions in irregular and high dimensional solution spaces. As a 2-link mechanical manipulator is a system with high dimensionsthat calculating its maximum load carrying capacity is an important issue, PSO and GA can be of great help in determining this capacity easily and efficiently.
\end{abstract}

Keywords: -Particle Swarm Optimization - Genetic Algorithm, manipulator

\section{INTRODUCTION}

In recent years, PSO and GA have been applied for different purposes to different systems as an optimization technique [3-5]. These two techniques have diverse abilities in searching the solution space with high dimensions and are efficient methods that perform well and can also be applied to the systems that their parameters might not be optimized easily using other techniques.

A 2-link mechanical manipulator is a system with high usage and one of the critical elements for it is calculating the maximum load capacity it can handle [6-8]. The nonlinear property of the manipulator model makes it challenging for the mathematical approaches to determine the maximum load although this is an important concept to be decided for the variety of the applications the mechanical manipulator has in the industry [7-9]. So the need for a method that is easier to be applied regarding the computation and analysis difficulty is essential. By applying the mentioned evolutionary techniques to a 2-link mechanical manipulator, it is possible to use PSO and GA's strong search abilities to determine the maximum load capacity of a high dimensioned 2-link mechanical manipulator easily and efficiently.

This paper is organized as follows. In section 2, 2-link mechanical manipulator, genetic algorithm, particle swarm optimization and the methodology is discussed. Section 3,4 and 5 are talking about applying genetic algorithm and particle swarm optimization to the estimated and Euler's shortest path and finding the constraints and section 6 describes the conclusion. Finally section 7 includes the references.

\section{THE OVERALL VIEW AND METHODOLOGY}

In this part an overall view is given to the problem. The 2-link mechanical manipulator is explained including the equations and genetic algorithm and particle swarm optimization that are used as optimization algorithms are discussed briefly and the methodology is described.

\subsection{2-Link Mechanical Manipulator}

The mechanical manipulator with elastic joints is formulated in this way:

$$
\begin{aligned}
& D_{11} \ddot{q}_{1}+D_{12} \ddot{q}_{3}-C \dot{q}_{1}^{2}-2 C \dot{q}_{1} \dot{q}_{3}+k\left(q_{1}-q_{2}\right)=0 \\
& D_{22} \ddot{q}_{3}+D_{12} \ddot{q}_{1}+C \dot{q}_{1}^{2}+k\left(q_{3}-q_{4}\right)=0 \\
& D_{11}=m_{1} L_{c 1}^{2}+I_{1}+m_{2}\left(L_{1}^{2}+L_{c 2}^{2}+2 L_{1} L_{c 2} \cos q_{3}\right) \\
& +I_{2}+m_{p}\left(L_{1}^{2}+2 L_{1} L_{c 2}^{2}+L_{2}^{2}+2 L_{1} L_{2} \cos q_{3}\right)+I_{p} \\
& D_{22}=m_{2} L_{c 2}^{2}+I_{2}+m_{p} L_{21}^{2}+I_{p} \\
& D_{12}=m_{2} L_{1} L_{c 2} \cos q_{1}+m_{2} L_{c 2}^{2}+I_{2}+m_{p} L_{1} L_{2} \cos q_{2} \\
& +m_{p} L_{2}^{2}+I_{p} \\
& C=m_{2} L_{1} L_{c 2} \sin q_{3}+m_{p} L_{1} L_{2} \sin q_{3}
\end{aligned}
$$

And the constraints 


$$
\begin{aligned}
& I_{r 1} \ddot{q}_{2}+k\left(q_{2}-q_{1}\right)<\tau_{1} \\
& I_{r 2} \ddot{q}_{4}+k\left(q_{4}-q_{3}\right)<\tau_{2} \\
& l_{1}=1, l_{2}=1, L_{c 1}=0.5, L_{c 2}=0.5, m_{1}=m_{2}=2 \\
& I_{1}=I_{2}=\frac{1}{6}, \tau_{1}=\tau_{2}=104
\end{aligned}
$$

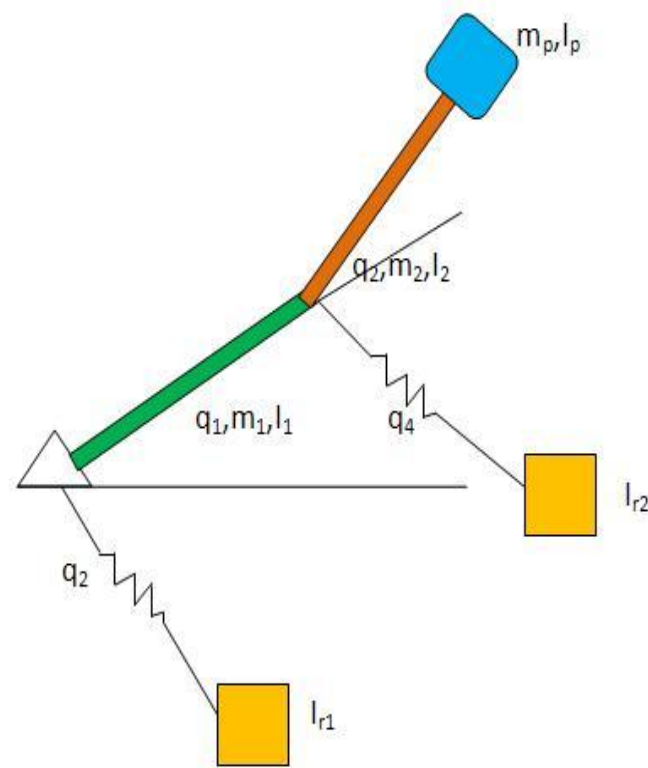

Figure(1). A 2-link mechanical manipulator

Figure(1). Shows a 2-link mechanical manipulator.

\subsection{Genetic Algorithm}

GA is a population search method that is used for optimization. GA's are a metaphoric abstraction of natural biologicalevolution. The basic concepts associated with naturalevolution which provide the underlying foundation for geneticalgorithms are natural selection, recombination named crossover and mutation. The evolutionary processof the GA takes place on chromosomes. Chromosomesare the biological edifices which contain the encoded geneticmaterial that determine the structure of the living things.Natural selection is the process bywhich chromosomes containing more highly fit encodingshave a greater probability of reproducing than those thathave weaker encodings. Once selected for reproduction,based upon the strength of their encodings, chromosomesrecombine, exchanging genetic material by the crossover. Mutation introduces variability by alteringchromosomes making them different from their parentchromosomes.

Simple genetic algorithms are GA's that are guidedlargely by the three operators: crossover,mutation and selection. Each chromosome represents a possible solution.

Through natural selection, chromosomes encoded withbetter possible solutions are chosen for recombinationyielding improved off-springs for successive generations.Natural evolution of the population continues until a predeterminednumber of generations is reached, resulting ina final generation of highly fit chromosomes representingoptimal or near optimal solutions to the problem. In this study the genetic algorithm used is applying elite selection as the selection strategy, dynamic mutation as the mutation strategy and uniform crossover as the crossover method. This combination that has been used here is chosen and proved to be effective by 'try and error' method.

\subsection{Particle Swarm Optimization}

PSO is a population-based method used for optimization. It is an evolutionarycomputation technique developed by Kennedy and Eberhart. It seemslike an appropriate time to step back and look at where weare, 
how we got here, and where we think we may be going.It iswritten from an engineering and computer scienceperspective, and is not meant to be comprehensive in areassuch as the social sciences. The applications already developed include human tremor analysis, powersystem load stabilization, and product mix optimization and many others.

The formulation of a variation of PSO called adaptive weighted PSO is as follows:

$$
\begin{aligned}
& v i(t)=w v_{i}(t-1)+a\left[r_{1}\left(x_{\text {localbesi }}-x_{i}(t)\right)+r_{2}\left(x_{\text {globalbesi }}-x_{i}(t)\right)\right] \\
& x_{i}(t)=v_{i}(t)+x_{i}(t-1) \\
& w=w_{0}+r\left(1-w_{0}\right) \\
& a=a_{0}+t / N t \quad t=1,2, \ldots, N t
\end{aligned}
$$

Here $v_{i}$ is the $\mathrm{i}^{\text {th }}$ particle velocity, $x_{i}$ is the $\mathrm{i}^{\text {th }}$ particle position, $\mathrm{t}$ is the current iteration, $\mathrm{Nt}$ is the maximum numbers of iterationsand the random numbers used are defined as shown below.

$\mathrm{r}, \mathrm{r}_{1}, \mathrm{r}_{2} \approx \mathrm{U}(0,1)$

$\mathrm{a}_{0}$ is $[0.5,1]$ and $\mathrm{w}_{0}[0,1]$

It has to be mentioned that AWPSO is more efficient than PSO itself as it changes the decision vectors magnitude according to the iteration that the search algorithm is traversing.

\subsection{Methodology}

According to Euler's equation $F_{y}-F_{y^{\prime}}=c t e$, finding the shortest distance is as follows:

$$
\begin{aligned}
& d l=d x \sqrt{1+y^{\prime 2}} \\
& J=\int \sqrt{1+y^{\prime 2}} d x \Rightarrow \\
& 0-\frac{y^{\prime}}{\sqrt{1+y^{\prime 2}}}=c t e \Rightarrow y=A x+B
\end{aligned}
$$

In order to find the minimum path and maximum payload, a first-order, second-order and thirdorderline equations are quite estimated close to a line that is the shortest path in section 3.

Regarding the general form of Euler's equation we come to estimate one of the shortest distances as a thirdorder line equation too, that is mentioned in section 4.

Another method for finding the shortest path is minimizing the mentioned constraints thatis elaborated in section 6.

\section{APPLYING PSO AND GA TO THE ESTIMATED SHORTEST PATH}

There are three cases elaborated here. There are also three points to decide the first and the final point of the line. The initial point is $(1,1)$ where the final points are $(-1,-1),(-1,1)$ and $(0,1.4)$. The points $(1,1)$ and $(-1,-$ $1)$ is assumed as set( $(1)$. The points $(1,1)$ and $(-1,1)$ are the initial and final points of set(2) and the points $(1,1)$ and $(0,1.4)$ contain the first and final points of set $(3)$.

Here at first the path is decided by estimating it close to a line that is proved to have the shortest distance. The distance between the points is divided into $\mathrm{n}$ sections and the points of the estimated line is calculated. Then the traversed angles that are teta 1 and tata 2 are calculated by the following formula.

$$
\begin{aligned}
& \cos \left(\theta_{2}\right)=\left(x^{2}+y^{2}-l_{1}^{2}-l_{2}^{2}\right) /\left(2 l_{1} l_{2}\right) \\
& \theta_{1}=\arctan \left(\frac{y}{x}\right)-\arctan \left[\frac{l_{2} \sin \left(\theta_{2}\right)}{l_{1}+l_{2} \cos \left(\theta_{2}\right)}\right]
\end{aligned}
$$

Then by adding the equations of the 2-link manipulator and finding $\mathrm{m}_{\mathrm{p}}$ where $\mathrm{m}_{\mathrm{p}}=\mathrm{f}\left(\mathrm{x}_{1}, \ldots, \mathrm{x}_{8}\right)$, the maximization of function $\mathrm{f}$ is done by PSO and GA. $\mathrm{X}_{\mathrm{i}}$ are the chromosomes in GA and particles in PSO. 


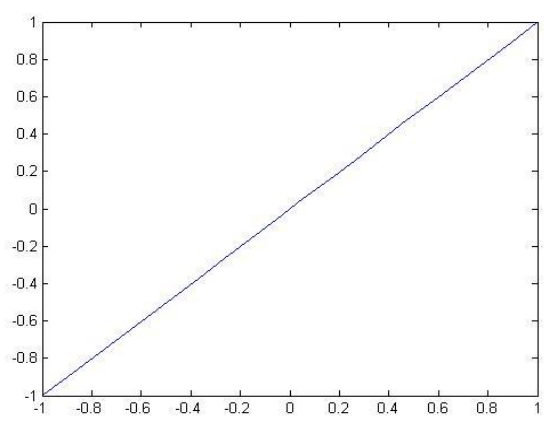

Figure(2). The traced line for set(1)

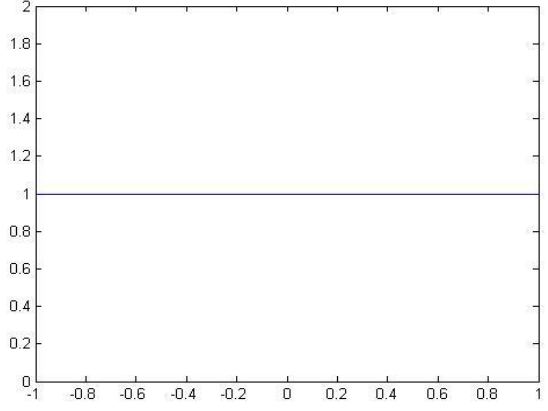

Figure(3). The traced line for set(2)

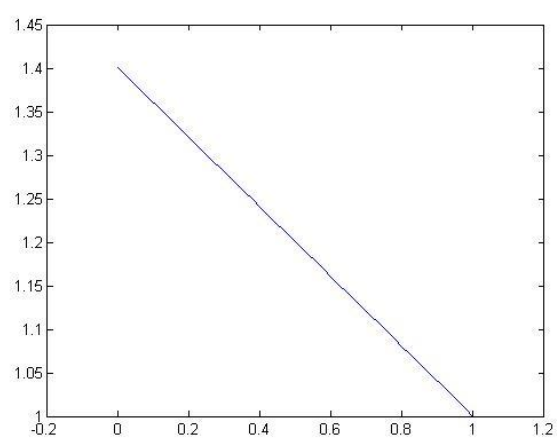

Figure(4). The traced line for set(3)

At first the shortest path is assumed to be a line. For example if figure(2-4) is the line that it has to trace, the angles that are traversed are shown in figures(5-7) where the red line indicates teta1 and the blue line indicates teta2. The computed maximum payload by PSO and GA is shown in table(1).

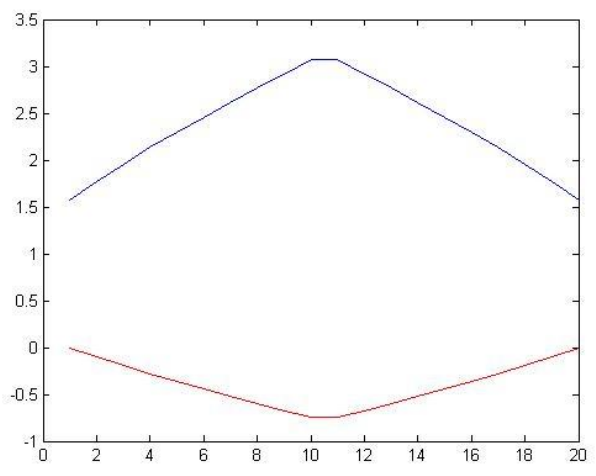

Figure(5). The Traversed Angles for set(1)

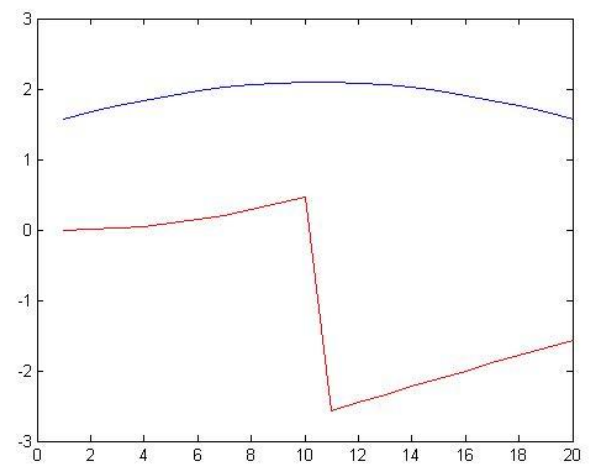

Figure(6). The Traversed Angles for set(2)

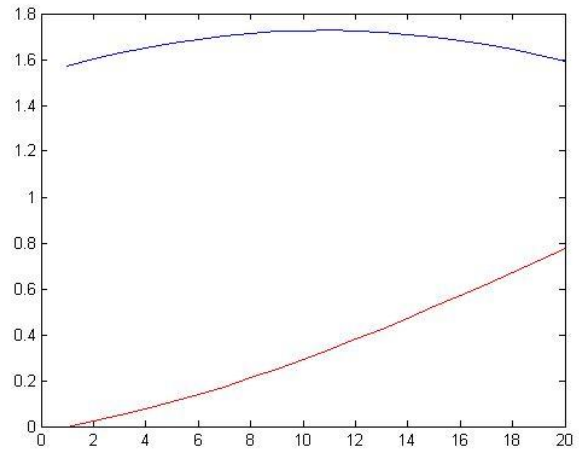

Figure(7). The Traversed Angles for set(3) 


\begin{tabular}{|l|l|l|l|}
\hline & Set(1) & $\operatorname{Set}(2)$ & $\operatorname{Set}(3)$ \\
\hline $\begin{array}{l}\text { Maximum } \\
\text { Payload } \\
\text { by PSO }\end{array}$ & 19.5078 & 24.2062 & 42.4392 \\
\hline $\begin{array}{l}\text { Maximum } \\
\text { Payload } \\
\text { by GA }\end{array}$ & 22.7218 & 24.0621 & 41.5156 \\
\hline
\end{tabular}

Table(1). The Maximum Estimated Payload by PSO and GA

The second estimated line is a second-order line estimated close to a line as follows. If $a x^{2} \cong b x$ then the equation will most likely present a short path.

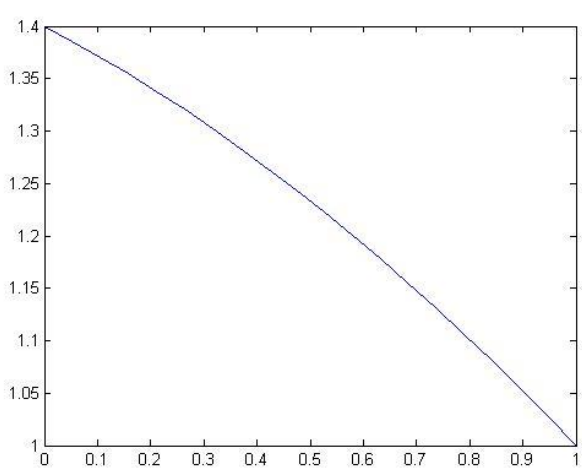

Figure(8). The traced line for set(1)

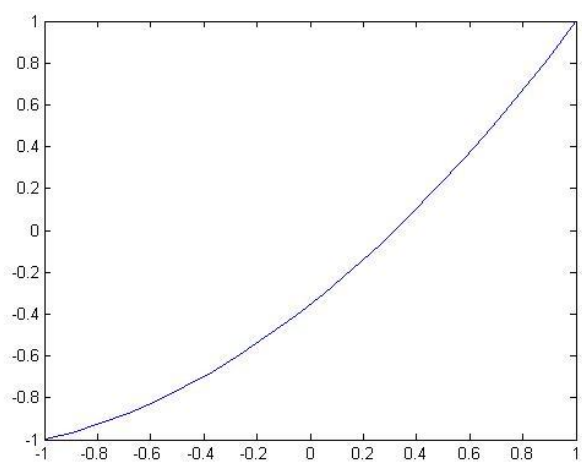

Figure(9). The traced line for set(2)

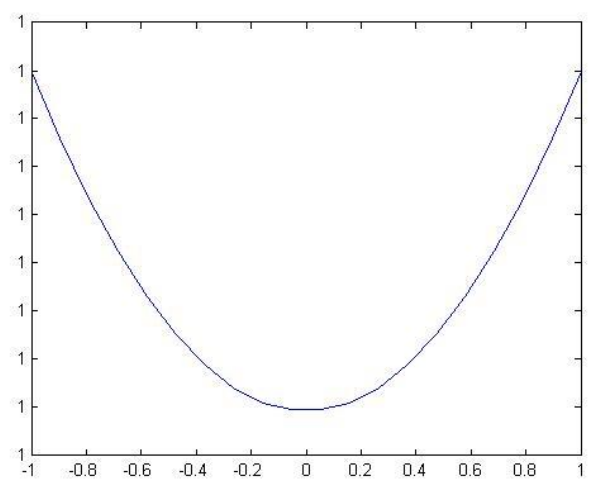

Figure(10). The traced line for set(3)

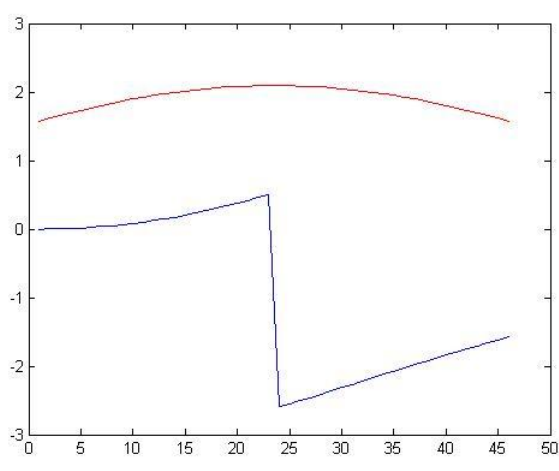

Figure(11). The Traversed Angles for set(1)

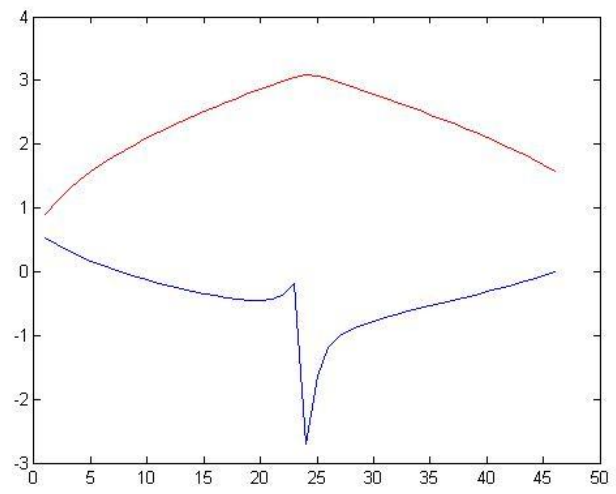

Figure(12). The Traversed Angles for set(2)

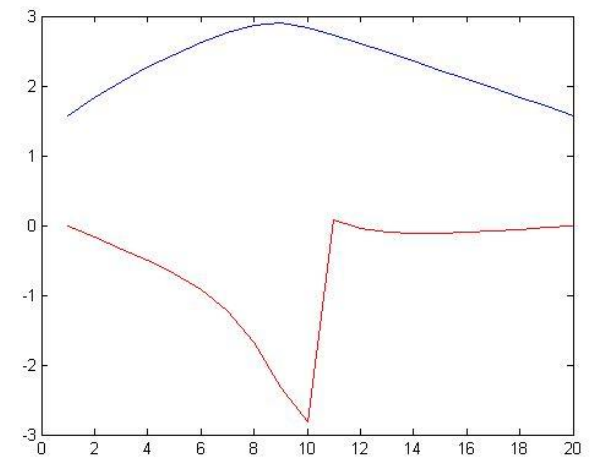

Figure(13). The Traversed Angles for set(3) 


\begin{tabular}{|l|l|l|l|}
\hline & $\operatorname{Set}(1)$ & $\operatorname{Set}(2)$ & $\operatorname{Set}(3)$ \\
\hline $\begin{array}{l}\text { Maximum } \\
\text { Payload } \\
\text { by PSO }\end{array}$ & 43.8069 & 32.2211 & 50.6492 \\
\hline $\begin{array}{l}\text { Maximum } \\
\text { Payload } \\
\text { by GA }\end{array}$ & 41.8124 & 34.0602 & 49.5107 \\
\hline
\end{tabular}

Table(2). The Maximum Estimated Payload by PSO and GA

The third estimation is done to fit a third-order equation by this way, $a x^{3}+b x^{2} \cong c x, a x^{3} \cong b x^{2}$ and the results are given as follows.

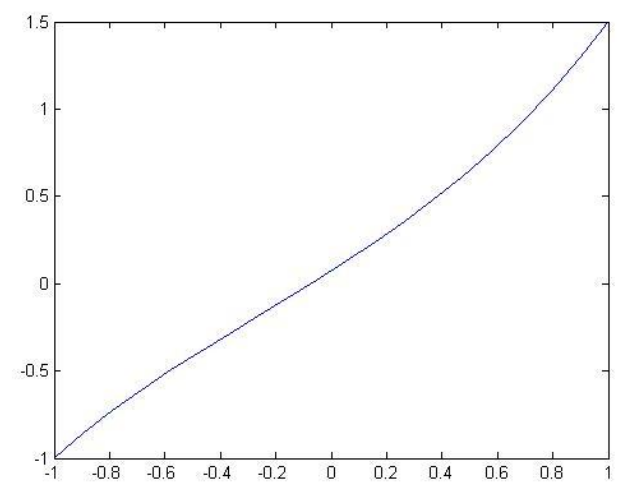

Figure(14). The traced line for set(1)

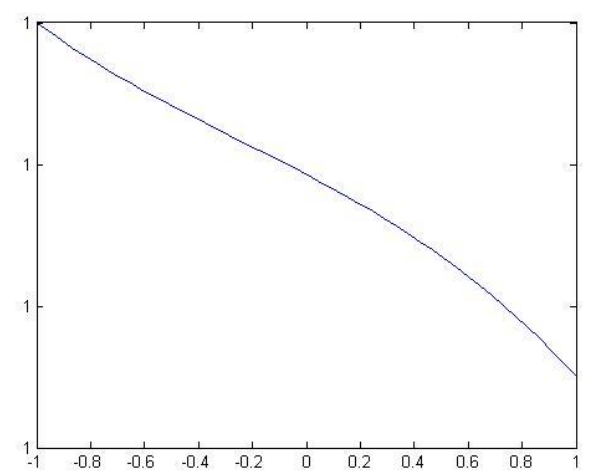

Figure(15). The traced line for set(2)

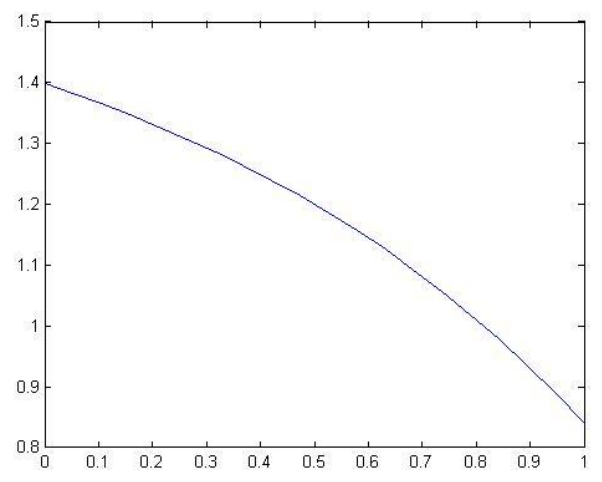

Figure(16). The traced line for set(3)

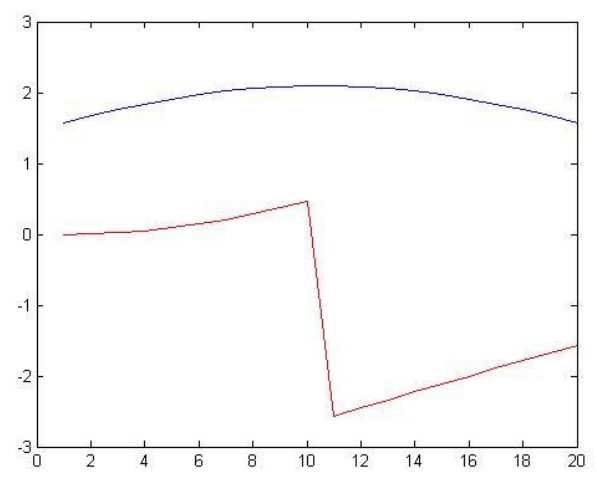

Figure(17). The Traversed Angles for set(1)

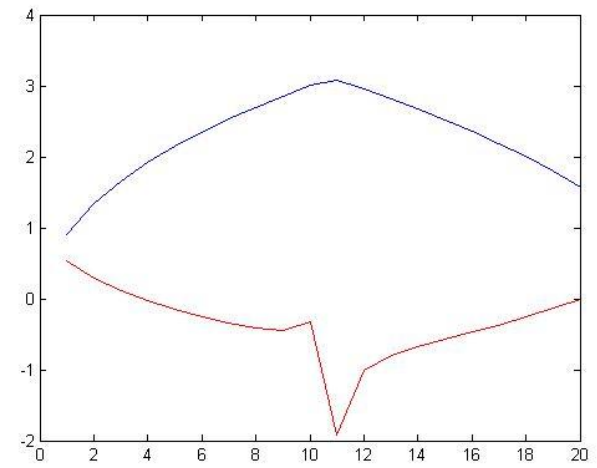

Figure(18). The Traversed Angles for set(2)

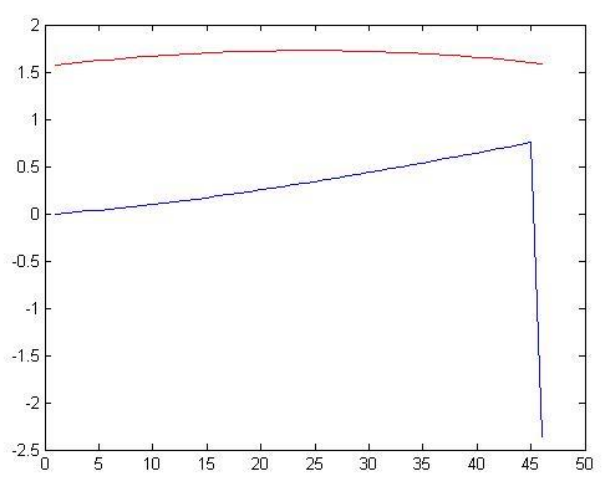

Figure(19). The Traversed Angles for set(3) 


\begin{tabular}{|l|l|l|l|}
\hline & Set(1) & $\operatorname{Set}(2)$ & $\operatorname{Set}(3)$ \\
\hline $\begin{array}{l}\text { Maximum } \\
\text { Payload } \\
\text { by PSO }\end{array}$ & 41.5233 & 34.6268 & 42.4392 \\
\hline $\begin{array}{l}\text { Maximum } \\
\text { Payload } \\
\text { by GA }\end{array}$ & 38.8089 & 38.2487 & 41.5156 \\
\hline
\end{tabular}

Table(3). The Maximum Estimated Payload by PSO and GA

\section{APPLYING PSO AND GA TO ONE OF THE EULER'S SHORTEST PATHS}

Regarding the general form of Euler's equation $F y=\frac{d}{d x} F y^{\prime}$ we come to estimate one of the shortest distances as a third-orderequation $y=a x^{3}+b x^{2}+c x+d$.

$$
\begin{aligned}
& d_{l}^{2}=d_{x}{ }^{2}+d_{y}{ }^{2}, J=\int d_{l} \rightarrow J=\int \sqrt{d_{x}{ }^{2}+d_{y}{ }^{2}} \Rightarrow \\
& J=\int \sqrt{1+y^{\prime 2}} d x \rightarrow F y=\frac{d}{d x} F y^{\prime} \\
& \Rightarrow y^{\prime \prime}\left(1+y^{\prime 2}\right)-y^{\prime 2}=0 \Rightarrow y^{\prime}\left(1+y^{2}\right)-y^{2}=0 \Rightarrow \\
& y^{\prime}=\frac{y^{2}}{1+y^{2}} \rightarrow y-\frac{1}{y}=x+c \Rightarrow \\
& y=\int \frac{x+c \pm \sqrt{(c+x)^{2}+4}}{2} d x \rightarrow \\
& y=\frac{1}{3} x^{3}+\left(c-\frac{1}{4}\right) x^{2}+\left(c^{2}+c+4\right) x+\left(\frac{c^{3}}{3}+c+a\right)
\end{aligned}
$$

and $\left(x_{1}, y_{1}\right)$ as initial

and $\left(x_{2}, y_{2}\right)$ as final point $s \Rightarrow$

$c^{2}\left(x_{2}-x_{1}\right)+c\left(x_{2}^{2}+x_{2}-x_{1}^{2}-x_{1}\right)+\frac{1}{3}\left(x_{2}^{3}-x_{1}^{3}\right)$

$-\frac{1}{4}\left(x_{2}^{2}-x_{1}^{2}\right)+4\left(x_{2}-x_{1}\right)-y_{2}+y_{1}=0$

The mentioned method leads us to one of theminimum defined paths.

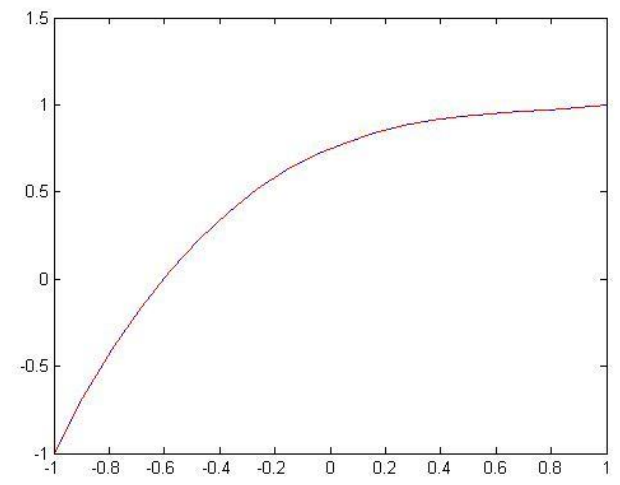

Figure(20). The traced line for set(1)

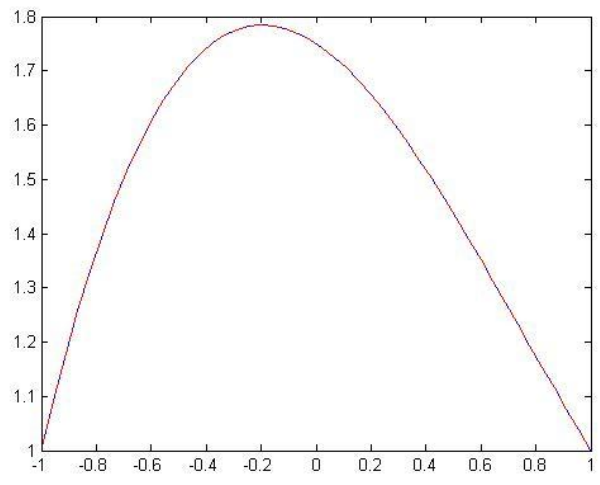

Figure(21). The traced line for set(2) 


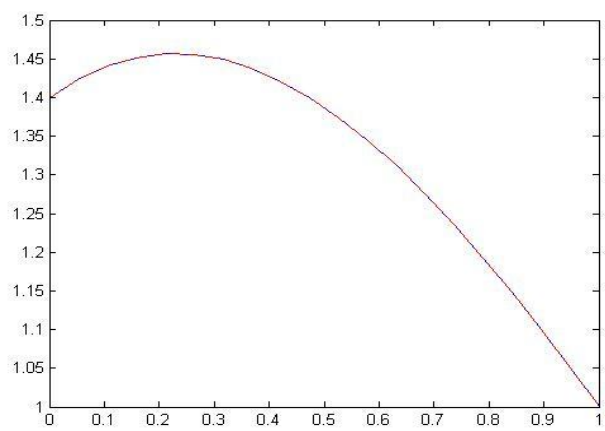

Figure(22). The traced line for set(3)

The above figures indicate the paths but the traversed angles are as follows.

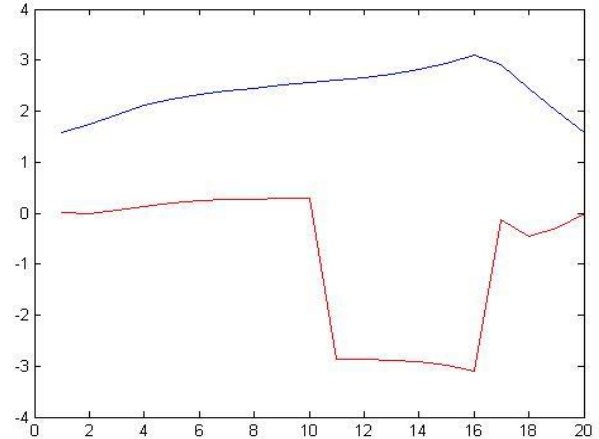

Figure(23). The Traversed Angles for set(1)

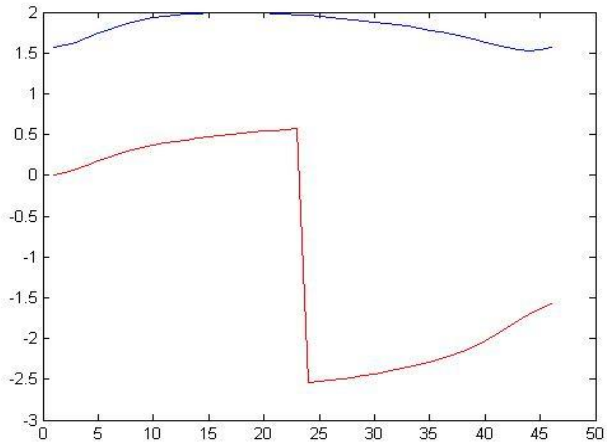

Figure(24). The Traversed Angles for set(2)

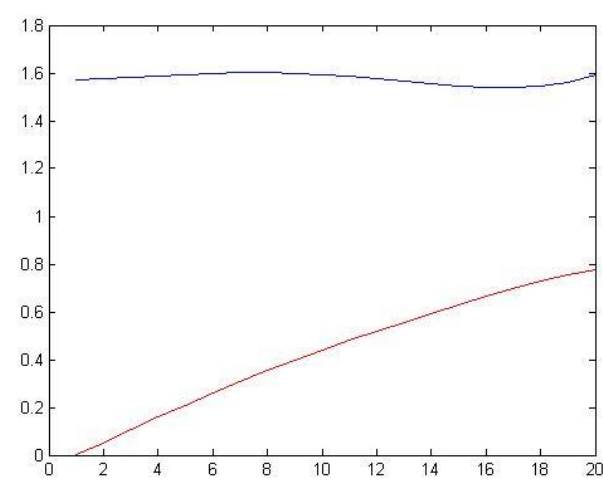

Figure(25). The Traversed Angles for set(3)

\begin{tabular}{|l|l|l|l|}
\hline & Set(1) & $\operatorname{Set}(2)$ & $\operatorname{Set}(3)$ \\
\hline $\begin{array}{l}\text { Maximum } \\
\text { Payload } \\
\text { by PSO }\end{array}$ & 32.9588 & 45.0383 & 39.4289 \\
\hline $\begin{array}{l}\text { Maximum } \\
\text { Payload } \\
\text { by GA }\end{array}$ & 30.2893 & 42.7166 & 42.1618 \\
\hline
\end{tabular}

Table(4). The Maximum Estimated Payload by PSO and GA

Another estimated option that we have in this case is a second-order equation. The paths and the angles are denoted as follows. 


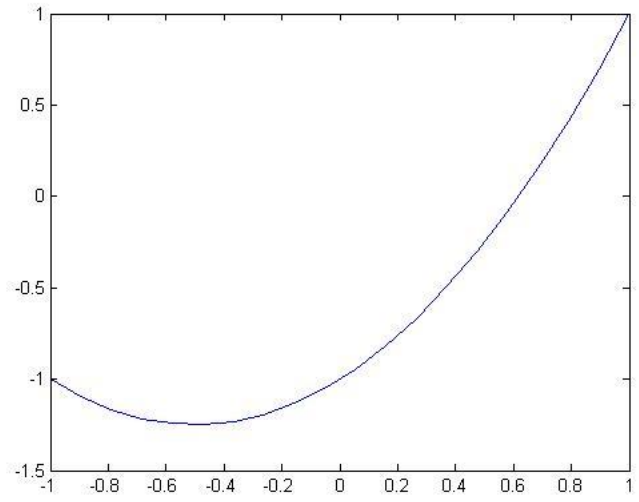

Figure(26). The traced line for set(1)

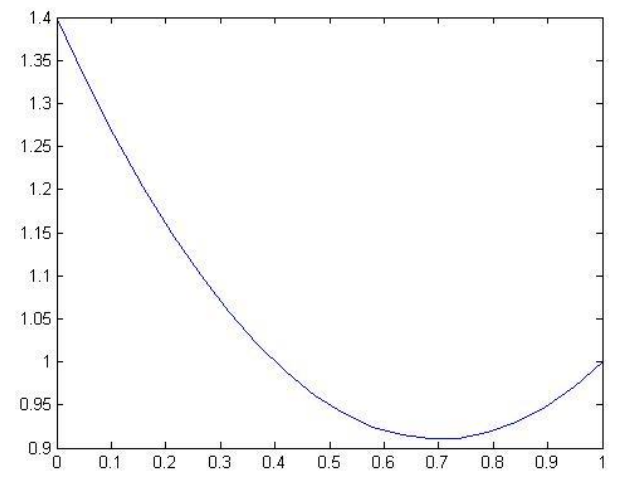

Figure(28). The traced line for set(3)

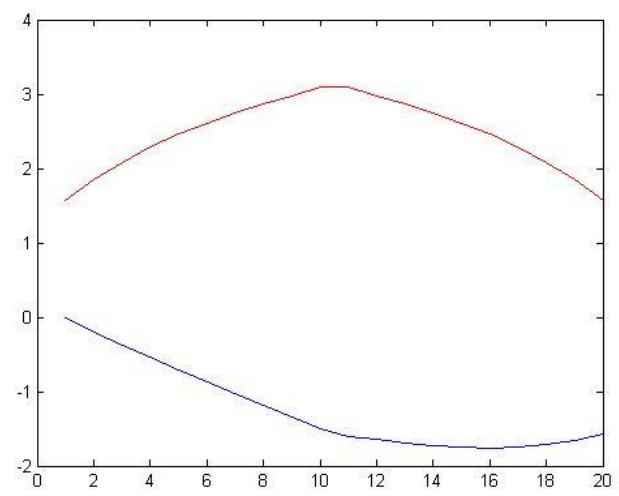

Figure(29). The Traversed Angles for set(1)

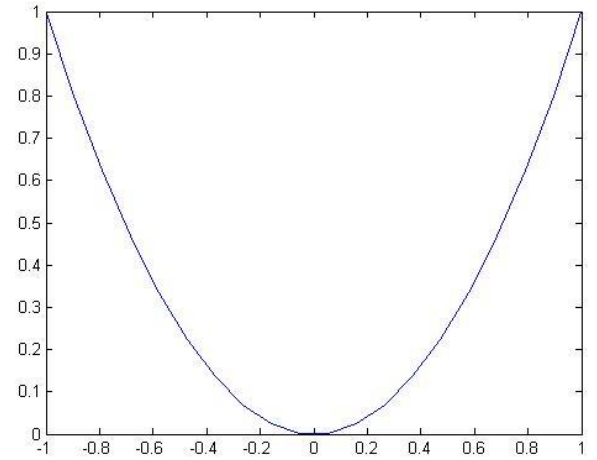

Figure(27). The traced line for set(2)

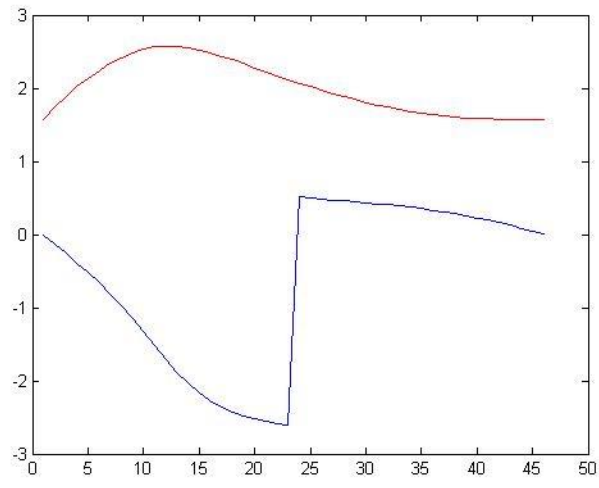

Figure(30). The Traversed Angles for set(2)

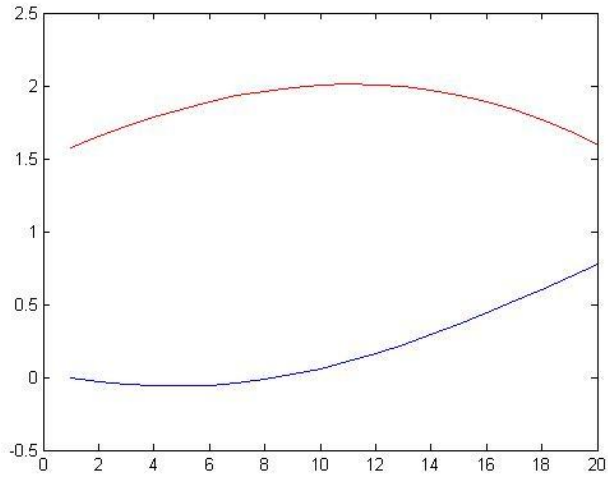

Figure(31). The Traversed Angles for set(3)

\begin{tabular}{|l|l|l|l|}
\hline & $\operatorname{Set}(1)$ & $\operatorname{Set}(2)$ & $\operatorname{Set}(3)$ \\
\hline $\begin{array}{l}\text { Maximum } \\
\text { Payload } \\
\text { by PSO }\end{array}$ & 35.6092 & 25.2855 & 45.9221 \\
\hline $\begin{array}{l}\text { Maximum } \\
\text { Payload } \\
\text { by GA }\end{array}$ & 37.4727 & 21.3270 & 43.5418 \\
\hline
\end{tabular}

Table(5). The Maximum Estimated Payload by PSO and GA

As it was mentioned the red color indicates teta1 and the blue color indicates teta2. 


\section{APPLYING PSO AND GA TO FIND THE CONSTRAINTS}

PSO and GA are used to minimize the torques included in the constraints.

$$
\begin{aligned}
& I_{r 1} \ddot{q}_{2}+k\left(q_{2}-q_{1}\right)<\tau_{1} \\
& I_{r 2} \ddot{q}_{4}+k\left(q_{4}-q_{3}\right)<\tau_{2}
\end{aligned}
$$

The path that is estimated in this way is a four-degree equation and having the initial and final points we have:

$$
y_{1}=x_{1}^{4}+a x_{1}^{3}+b x_{1}^{2}+c x_{1}+d y_{2}=x_{2}^{4}+a x_{2}^{3}+b x_{2}^{2}+c x_{2}+d
$$

Here having four parameters with two equations we can find two of the parameters using the equations. The other two parameters are found by PSO and GA including minimizing the torque. It has to be mentioned that in the above-mentioned equations the parameters $\mathrm{x}$ are time $(\mathrm{t})$ and the parameters $\mathrm{y}$ are the angles (teta1 and teta2). In this method the maximum load is fed as $10 \mathrm{~kg}$ to the system.

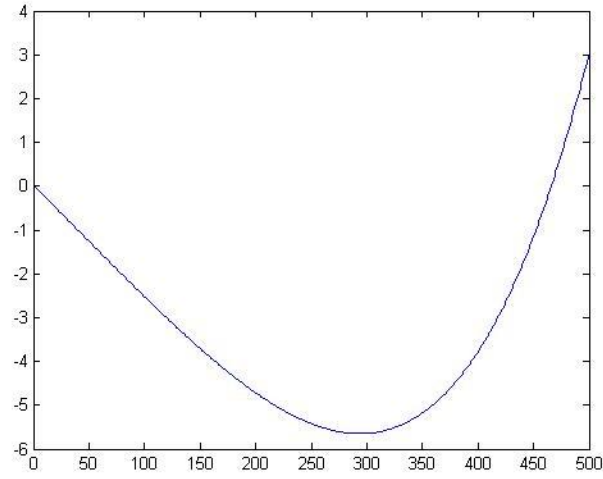

Figure(32). The angle teta1 estimated by GA

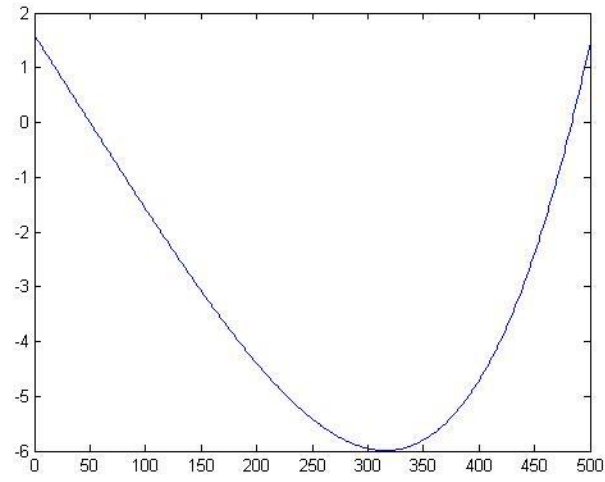

Figure(33). The angle teta2 estimated by GA

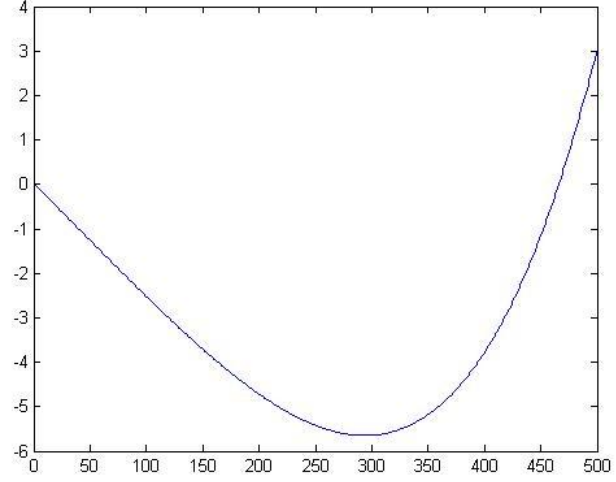

Figure(34). The angle teta1 estimated by PSO

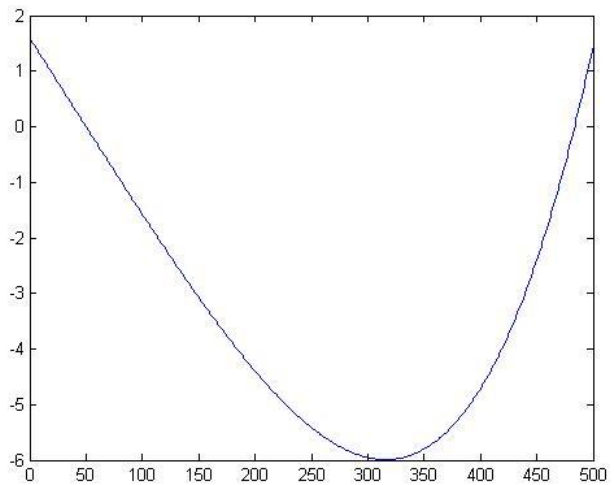

Figure(35). The angle teta2 estimated by PSO

\section{CONCLUSION}

There are many different techniques for calculating the maximum payload in a 2-link manipulator. PSO and GA are two population-based methods that can be used for optimization problems. The mathematical solutions can also be of great help in this regard. Here some solutions and their paths are taken into account. The main advantage of using the population-based methods like GA and PSO in solving this problem is the operational simplicity when they are implemented. These optimization algorithms are able to solve the problem using some simple operations like subtraction and addiction. Since the achieved results are show that these methods have had a good performance, considering the simplicity of using them, it is advisable to apply them to calculate the manipulator's attributes. 


\section{REFERENCES}

[1] IEEE transactions on systems, man, and cybernetics, (2000), vol. 24, no. 4.

[2] Meghdari, A., Naderi, D., \&Alam, M. R. Neural-network-basedobserver for real-time tipover estimation,Mechatronics,(2005), vol.15, no. 8, 989-1004.

[3] Chiu, C. S., Lian, K. Y., \& Wu, T. C. Robust adaptive motion/forcetracking control design for uncertain constrained robot manipulators. Automatica,(2004), vol. 40, no. 12, 2111-2119.

[4] Dudrík, J., High-Frequency Soft-Switching DC-DC Power Converters.Proc.of the II. Internal Scientific Conf.ofthe Faculty of Electrical Engineeringand Informatics, Košice, (2001), pp.45-46.

[5] Bauer P., Duijsen P.J. van, Challengesand Advances in Simulation, PESC (2005), Brazil.

[6] T. Ravichandran, D. Wang and G. Heppler, "Simultaneous plant-controller design optimization of a two-link planar manipulator", Journal of Mechatronics, vol. 16, (2006), pp. 233-242.

[7] K. Abdel-Malek and J. Yang, "Sweeping of an object held by a robotic end-effector", Journal of Robotics and Computer - Integrated manufacturing, vol. 21, (2005), pp. 159-173.

[8] J. W. S. Chong, S. K. Ong, A. Y. C. Nee and K. Youcef-Youmi, "Robot programming using augmented reality: An interactive method for planning collision free paths", Journal of Robotics and Computer - Integrated manufacturing, 2004.

[9] Z. Shiller and H. H. Lu, "Computation of path constrained time optimal control motions with dynamic singularities", Transaction of ASME Journal of Dynamic Systems, Measurement and Control, vol. 114, no. 2, (1998), pp. 34-40. 